\title{
Genome-wide analysis of alternative reproductive phenotypes in honeybee workers
}

\author{
DRIES CARDOEN,$*+$ TOM WENSELEERS,† ULRICH R. ERNST $, *+E L L E N ~ L . ~ D A N N E E L S, \ddagger$ DRIES \\ LAGET, $\ddagger$ DIRK C. DE GRAAF, $\ddagger$ LILIANE SCHOOFS* and PETER VERLEYEN* \\ ${ }^{*}$ Research Group of Functional Genomics and Proteomics, K.U. Leuven, Naamsestraat 59, B-3000 Leuven, Belgium, +Laboratory \\ of Entomology, K.U. Leuven, Belgium, łLaboratory of Zoophysiology, Ghent University, Ghent, Belgium
}

\begin{abstract}
A defining feature of social insects is the reproductive division of labour, in which workers usually forego all reproduction to help their mother queen to reproduce. However, little is known about the molecular basis of this spectacular form of altruism. Here, we compared gene expression patterns between nonreproductive, altruistic workers and reproductive, non-altruistic workers in queenless honeybee colonies using a whole-genome microarray analysis. Our results demonstrate massive differences in gene expression patterns between these two sets of workers, with a total of 1292 genes being differentially expressed. In nonreproductive workers, genes associated with energy metabolism and respiration, flight and foraging behaviour, detection of visible light, flight and heart muscle contraction and synaptic transmission were overexpressed relative to non-reproductive workers. This implies they probably had a higher wholebody energy metabolism and activity rate and were most likely actively foraging, whereas same-aged reproductive workers were not. This pattern is predicted from evolutionary theory, given that reproductive workers should be less willing to compromise their reproductive futures by carrying out high-risk tasks such as foraging or other energetically expensive tasks. By contrast, reproductive workers mainly overexpressed oogenesis-related genes compared to nonreproductive ones. With respect to key switches for ovary activation, several genes involved in steroid biosynthesis were upregulated in reproductive workers, as well as genes known to respond to queen and brood pheromones, genes involved in TOR and insulin signalling pathways and genes located within quantitative trait loci associated with reproductive capacity in honeybees. Overall, our results provide unique insight into the molecular mechanisms underlying alternative reproductive phenotypes in honeybee workers.
\end{abstract}

Keywords: Altruism, Apis mellifera, microarray, reproductive division of labour

Received 30 November 2010; revision revised 21 June 2011; accepted 24 June 2011

\section{Introduction}

The reproductive division of labour in eusocial insects, in which the workers usually forego all reproduction in order to help rear siblings, represents one of the most spectacular examples of altruism in nature, as well as a classic Darwinian paradox (Darwin 1859; Ratnieks \& Wenseleers 2008; Ratnieks et al. 2011). Indeed, it is not trivial to explain how a genetic trait that confers steril-

Correspondence: Dries Cardoen, Fax: +32 163239 02;

E-mail: dries.cardoen@bio.kuleuven.be ity on its bearer would ever be able to spread in a population (Ratnieks et al. 2011). Over the last decades, however, great progress has been made in understanding what evolutionary factors drive worker sterility in insect societies. For example, based on inclusive fitness theory (Hamilton 1964), it is now understood that the incentive for workers to try to reproduce is set by a cost/benefit ratio in which factors such as relatedness, colony-level costs, and the presence of 'policing' mechanisms, which result in the selective removal of workerlaid eggs, all play a role (Wenseleers \& Ratnieks 2006; Ratnieks \& Wenseleers 2008). Policing is best known 
from the honeybee, where c. $98 \%$ of all worker-laid eggs are policed by other workers (Ratnieks \& Visscher 1989; Wenseleers \& Ratnieks 2006) and only c. 0.01$0.1 \%$ of the workers try to reproduce by activating their ovaries in presence of the queen (Ratnieks 1993). The presence of worker policing, in turn, has been explained based on the fact that honeybee queens mate with multiple drones (Palmer \& Oldroyd 2000), and that this causes the workers to be collectively more related to the queen's offspring than to the offspring of other workers (Ratnieks 1988; Wenseleers \& Ratnieks 2006).

Despite the fact that the evolution of altruism and worker sterility is now understood fairly well at an ultimate level, at a more proximate, mechanistic level many important questions remain. In fact, despite the postulation of 'genes for altruism' by hundreds of studies in evolutionary biology, very little is known about the actual underlying molecular mechanisms and gene regulatory networks that control worker reproduction and worker sterility, even in the honeybee - the best studied species in this respect (Thompson et al. 2006, 2008; Grozinger et al. 2007).

In honeybees, each colony usually has one reproductively active queen, and tens of thousands of mostly sterile workers (Ratnieks 1993). The development of young larvae into either queens or workers depends on the amount and type of food received during early larval development, which activates, among others, various epigenetic developmental switches (Kucharski et al. 2008). This leads to a high juvenile hormone (JH) titre in queen larvae (Rembold 1987), and via the insulin/insulin-like (IIS) and TOR (target of rapamycin) signalling pathways (Wheeler et al. 2006; Corona et al. 2007; Patel et al. 2007; de Azevedo \& Hartfelder 2008), resulting in the complete development of the queen's ovaries, consisting of c. 150-180 ovarioles per ovary (Sakagami \& Akahira 1958; Snodgrass 1984). Future worker bees, on the other hand, are fed with less royal jelly and more sugars, which leads to lower $\mathrm{JH}$ titres (Rachinsky \& Hartfelder 1990; Rachinsky et al. 1990) and to the destruction of nearly all ovarioles by apoptosis (Capella \& Hartfelder 1998), resulting in the formation of only 3-26 ovarioles per ovary (Snodgrass 1984). In presence of the queen or young female larvae, the workers generally do not activate their ovaries (Winston 1987; Ratnieks 1993). In these situations, pheromones released by the queen and brood result in an inhibition of worker ovary activation (Mohammedi et al. 1998; Hoover et al. 2003; Slessor et al. 2005; Maisonnasse et al. 2010). Nevertheless, upon loss of the mother queen, and upon subsequent failure to rear a replacement queen, as many as $30 \%$ of the workers develop their ovaries (Miller \& Ratnieks 2001), with the exact proportion depending on various social, nutritional and genetic factors (Hoover et al. 2003, 2006; Amdam et al. 2004, 2006; Schafer et al. 2006).

Interestingly, in adult honeybees, and in contrast to bumblebees and many other insects (Bloch et al. 2000), oogenesis and ovarian activation in adult workers is not influenced by JH (Robinson et al. 1991, 1992; Robinson \& Vargo 1997). Instead, JH regulates, together with vitellogenin, the age-related division of labour, including the transition from nurse to forager (Robinson \& Vargo 1997; Robinson \& Huang 1998; Guidugli et al. 2005). On the other hand, ecdysteroids are known to regulate vitellogenin synthesis in honeybee larvae (Barchuk et al. 2002) and the titres of the ecdysteroid 20-hydroxyecdysone (20E) appear to be slightly elevated in egg laying workers in queenless honeybee colonies (Robinson et al. 1991), but see Hartfelder et al. (2002) for a corollary.

Our hypothesis is that environmental information is perceived in the workers' antennae and that this input signal is further processed in the central nervous system. This, on its turn, generates signals towards the rest of the body, which control the activation of the ovaries. However, during these processing and signalling events other physiological systems, such as the metabolism might be targeted as well. The aim of this study was to obtain a more detailed picture of gene regulatory networks involved in worker reproduction and sterility. Therefore, we used a whole-genome microarray to identify the genes which are differentially expressed between nonreproductive 'altruistic' honeybee workers and reproductive 'selfish' ones in a queenless honeybee colony. In contrast to earlier studies, the main novelties are, first, our study used a whole-genome microarray vs. earlier EST-based micorarrays (e.g. Whitfield et al. 2003; Thompson et al. 2006; Grozinger et al. 2007). Second, we analysed normal, wild-type European honeybees, Apis mellifera carnica, as opposed to special strains of 'anarchistic' bees or bees selected for a high 'pollen hoarding' phenotype, which have unusually high proportions of egg-laying workers, or bees with higher numbers of ovarioles respectively (Barron et al. 2001; Amdam et al. 2006; Thompson et al. 2006, 2008). Third, we looked at gene expression throughout the whole body, as opposed to brain gene expression (Grozinger et al. 2007). Fourth, we analysed bees collected from natural, though hopelessly queenless colonies with a normal age structure and kept under entirely natural conditions, unlike caged bees (Grozinger et al. 2007). Fifth, we focused on relatively older bees (18 days) than used in earlier studies (e.g. 4 days in Thompson et al. 2006, 2008 and 10-day old in Grozinger et al. 2007) allowing us to compare nonreproductive workers with reproductive ones that had fully mature ovaries. 
The specific aims of our study were, first, the identification of the major gene classes that are differentially expressed between reproductive and nonreproductive honeybee workers. This was done using detailed gene ontology (GO) - enrichment analyses. Second, by comparing our results with those of earlier gene expression studies (Grozinger et al. 2003, 2007; Thompson et al. 2006, 2008; Kocher et al. 2008; Alaux et al. 2009a) as well as with QTL-studies on the reproductive capacity of worker bees (Oxley et al. 2008; Linksvayer et al. 2009), we show how the altered physiology of reproductive and non-reproductive worker bees is reflected in expression differences in a wide range of pathways, including ovary maturation, metabolic rate and activity levels, neural processes and many others. Third, since evolutionary theory predicts that reproductive workers should tend to avoid carrying out risky tasks (Franks \& Scovell 1983; Bourke 1988), and behavioural studies showed that non-reproductive honeybee workers display higher work rates than reproductive ones, and an earlier onset of foraging (Hillesheim et al. 1989; Martin et al. 2002; Dampney et al. 2004; Oldroyd \& Beekman 2008), we tested whether such a pattern can also be distilled from our data. Finally, our study tried to generate a list of potential key regulatory switches involved in activating or suppressing ovary development in honeybee workers, based on previous analyses and gene classes generally known for their key-regulating functions, e.g. ecdysteroid induced genes (Beckstead et al. 2005), neuropeptides (Hummon et al. 2006; Boerjan et al. 2010), odorant binding proteins and receptors (Foret \& Maleszka 2006) and others.

\section{Materials and methods}

\section{Sample collection}

Two bee colonies (A. mellifera carnica), headed by an instrumentally inseminated single-mated queen (obtained from the DLR Fachzentrum für Bienen und Imkerei, Mayen, Germany) were kept at the experimental beekeeping facility of the Laboratory of Zoophysiology of Ghent University, Belgium. To induce worker reproduction, both colonies were dequeened in the beginning of August 2008, and any newly built queenrearing cells were removed in order to maintain the queenless condition. Broodframes with emerging brood were placed in an incubator at $34^{\circ} \mathrm{C}$ and high relative humidity. For 5 days, newly emerged bees were marked with a paintdot on their thorax using a dayspecific colour code (Posca paint-markers), and then introduced into their queenless colony of origin. Eighteen-day-old workers were recaptured in the early morning and immediately anesthetized on ice and dissected to score ovary-development by making two lateral incisions in the abdomen. Note that the dissection pad was cooled with ice. If the length of the largest oocyte was greater than $1.1 \mathrm{~mm}$ (c. $50 \%$ the size of a freshly laid egg), the ovary was scored as developed; if the length of the largest oocyte was smaller than $0.3 \mathrm{~mm}$, the ovary was scored as undeveloped. Dissections always took less than $35 \mathrm{~s}$ per sample. All samples were immediately frozen in liquid nitrogen and stored at $-80{ }^{\circ} \mathrm{C}$ until RNA-extraction which was performed on individual whole bees. Intermediate stages of oocyte development were not studied. From each colony, eight bees with fully developed ovaries and eight bees with undeveloped ovaries were analysed. Subsequently, we will refer to these bees as reproductive and nonreproductive ones (note we did not monitor egg-laying behaviour). RNA-extraction was carried out on individual bees with the RNeasy - lipid tissue kit (Qiagen) using manufacturers' guidelines on individual bees. RNA was eluted in two batches of 50 and $30 \mu \mathrm{L}$ RNase free water, both of which were pooled for further analysis.

\section{Microarray analysis}

Microarray hybridizations were performed by the VIB MicroArray Facility (Flemish Institute for Biotechnology), using a newly developed Agilent whole-genome honeybee microarray, which contained 15187 probes targeting all but 177 of the 11062 coding sequences represented in the Prerelease 2 version of the honeybee Official Gene Set (OGSPrls2) available on Beebase (genomes.arc.georgetown.edu/downloadFASTA.html)

(details in Data S1). RNA concentration and purity were determined using the Nanodrop ND-1000 (Nanodrop Technologies) and RNA integrity was assessed using a Bioanalyser 2100 (Agilent). Per sample, an amount of $1 \mu \mathrm{g}$ of total RNA spiked with 10 viral polyA transcript controls (Agilent RNA Spike-In Kit) was converted to double stranded cDNA in a reverse transcription reaction. Subsequently, the sample was converted to antisense cRNA, amplified and labelled with Cyanine 3-СТР (Су3) or Cyanine 5-СТP (Су5) in an in vitro transcription reaction according to the manufacturer's protocol (Agilent). A mixture of purified, labelled cRNA (Cy3 label: 14 pmol; Cy5 label: 10 pmol) was hybridized on the Agilent $8 \times 15 \mathrm{~K}$ honeybee array, followed by (manual) washing according to the manufacturer's procedures. To assess the raw probe signal intensities, arrays were scanned using the Agilent DNA MicroArray Scanner with SureScan High-Resolution Technology and probe signals were quantified using Agilent's Feature Extraction software (version 10.1.1.1). 
All samples were hybridized using a direct comparison balanced block dye swap design, and each two-colour array was performed with samples dissected on the same day, originating from bees collected from the same colony. In total, we compared RNA extracts of eight reproductive and eight nonreproductive individual workers collected each from two experimental colonies, resulting in the analysis of a total of 16 two-colour arrays.

\section{Differential expression analysis}

To test for differential expression we first prefiltered the Agilent Feature Extraction unprocessed signals to retain only those probes which had at least one significant hybridisation in one of the channels of the arrays. This resulted in a dataset containing 14248 probes representing 10334 genes. Next, the red and green channels were normalised within and between arrays using loess and quantile normalisation in the Bioconductor package limma (Smyth 2005). For the genes with two available probes, we only retained the probe with the highest average expression, since that could be measured with the greatest accuracy and the least amount of noise. Finally, differential expression was assessed using empirical Bayes moderated $t$-tests carried out in limma (Smyth 2005) on the combined dataset of both colonies. In this analysis, colony was included as a random blocking variable and $p$-values were false discovery rate (FDR) corrected using the Benjamini-Hochberg method (Benjamini \& Hochberg 1995). All genes with an adjusted $p$-value smaller than 0.05 were considered as differentially expressed and were used for further functional analysis. The gene expression data from this study have been deposited at ArrayExpress (http:// www.ebi.ac.uk/arrayexpress, access nr. E-TABM-1003). We performed additional quantitative real time PCR (qRT PCR) analyses in order to validate the microarray. Sample collection, methods and results are available in the Supporting information.

\section{Functional analysis}

First, genes of the OGSPrls2 were annotated with GO information collected from Uniprot and DAVID, from Drosophila orthologs included in Flybase and Uniprot, from a Blast2Go search (Gotz et al. 2008), as well as based on the presence of conserved PFAM protein domains with known function (see Data S1). Subsequently, we tested which biological process GO terms were significantly enriched among the sets of genes that were differentially expressed in reproductive and nonreproductive workers using the Bioconductor TopGO package, using the modified hypergeometric test-based method 'elim' (Alexa et al. 2006). When a given gene was annotated with several different GO-terms, the term that was maximally enriched was given priority in the annotation of its putative function.

\section{Overlap with other studies and candidate gene sets}

Exact hypergeometric one-tailed Fisher-exact tests were used to determine the significance of overlap between the sets of genes that were differentially expressed in reproductive and nonreproductive workers in our dataset and various other candidate gene sets (Table S2). In addition, to test whether the overlap in the expression pattern of the different studies (upregulated, downregulated or not differentially expressed) was in the predicted direction, we used one-tailed Spearman Rank Correlation tests. Candidate gene sets included (1) differentially expressed genes identified in reproductive vs. nonreproductive and anarchistic vs. wild-type bees (Thompson et al. 2006, 2008; Grozinger et al. 2007), (2) genes which were inferred to be involved in determining ovary activation in honeybee queens (Kocher et al. 2008), (3) genes that are known to respond to exposure to QMP (Grozinger et al. 2003), or BP (Alaux et al. 2009a), (4) genes contained within various quantitative trait loci (QTL) linked to worker reproductive potential (OvA1-OvA4 linked to the anarchistic worker phenotype, Oxley et al. 2008 and L1-L2 linked to variation in worker ovariole numbers, Linksvayer et al. 2009). We also looked at genes known to be regulated by 20 hydroxyecdysone (20E) (Beckstead et al. 2005) and genes coding for neuropeptide hormones (Hummon et al. 2006) and their receptors, because they regulate a wide range of physiological processes, including reproduction (Hartfelder et al. 1995, 2002; Lindemans et al. 2009). For the association with the candidate gene sets, we only included genes which were above background in both studies as the relevant gene universe. To calculate the overlap with QTL studies, we only included the genes which had been successfully mapped to a particular chromosome in the Amel 4.0 assembly.

\section{Results}

Differentially expressed genes in reproductive vs. nonreproductive workers

In total, 1292 genes were differentially expressed (adjusted $p$-value $<0.05$ ), 740 of which were upregulated in reproductive workers and 552 were upregulated in nonreproductive workers (Fig. 1). Out of these, 318 genes showed a more than 1.5-fold upregulation, 293 in reproductive workers and 25 were upregulated in non- 

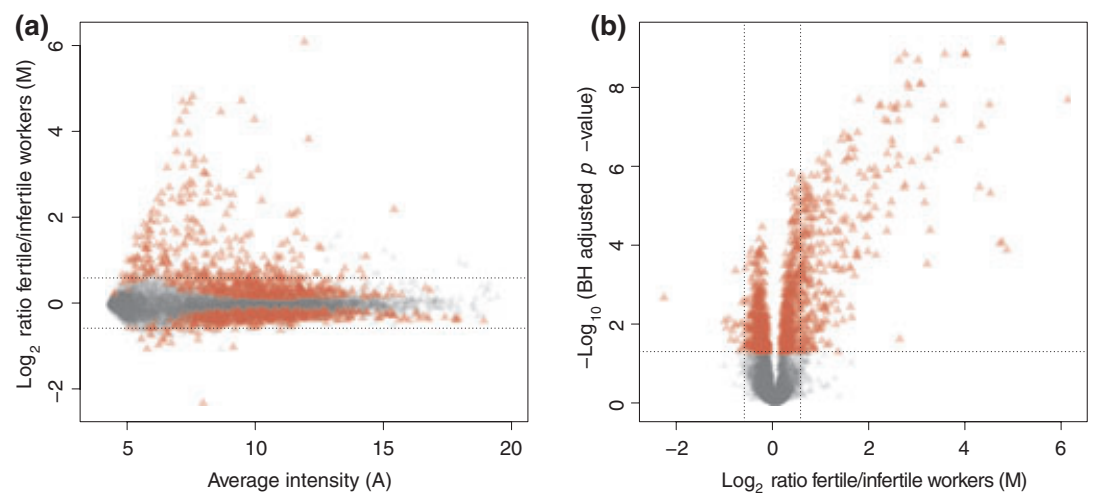

Fig. 1 Sets of genes which were differentially expressed between reproductive and nonreproductive workers, displayed as an MA plot (a) and a Volcano plot (b). Significantly differentially expressed genes (Benjamini-Hochberg adjusted $p$-values $<0.05$ ) are highlighted in red; the Log-ratio cutoff lines show genes that were more than 1.5-fold differentially expressed.

reproductive workers (Fig. 1). Overall, a total of 1144 out of the $1292(89 \%)$ differentially expressed genes could be annotated with GO information and were subjected to further functional analysis, 669 of which upregulated in reproductive workers and 475 in nonreproductive ones. Results of technical and biological validation experiments by means of $\mathrm{qRT}$ PCR are presented in the Supporting information.

\section{Overlap with other microarray studies}

There was no significant overlap between the genes that were differentially expressed in our study and those found to be differentially expressed in the brains of reproductive vs. nonreproductive workers Grozinger et al. 2007 (tests 1-3, Table S2), or in the brains and abdomens of anarchistic vs. wild-type honeybees (Thompson et al. 2006, 2008) (tests 4-6, Table S2). Nevertheless, a complete list of genes which were found to be differentially expressed in the same way in Grozinger et al. (2007) and Thompson et al. (2006, 2008) are provided in Table S1 and a selection of genes is displayed in Figs 2 and 3. The weak association with the study of Grozinger et al. (2007) may be due to the fact that it looked at differences in brain gene expression in 10-day-old, caged bees, whereas we used RNA extracts of whole bodies of 18-day-old bees, which were not caged but obtained from natural, queenless colonies. The nonsignificant association with the studies of Thompson et al. $(2006,2008)$ was expected given the small number of differentially expressed genes found in these studies, 4 and 7 , respectively, and the fact that these studies used much younger bees, of only 4 days old and of a specific anarchistic strain. In addition, there is no correlation with the study of Brito et al. comparing normal and $\mathrm{CO}_{2}$ treated worker bees (test 76, Table S2, Brito et al. 2010).
In contrast to the above studies, we did find a significant overlap with the microarray study of Kocher et al. (2008) on differential gene expression in honeybee queens with variable ovary activation. In particular, there was a significant association between genes being upregulated in nonreproductive workers in our study and those being upregulated in virgin relative to laying queen ovaries (test 11, Fisher exact test, $p=0.02$, Table S2). In addition, there was a nearly significant trend for genes which were upregulated in reproductive workers compared to genes which are upregulated in the ovaries of laying relative to mated queen (test 7 , Fisher exact test, $p=0.06$, Table S2) and in the brains of mated relative to virgin queen (test 22, Fisher exact test, $p=0.07$, Table S2). Furthermore, there was a significant association between the expression status of genes in our study and that in laying relative to mated, non-laying queen ovaries in Kocher et al. 2008 (test 9, Spearman rank correlation test, $p=0.009$, Table S2). For examples see Figs 2 and 3 and Table S1.

Interestingly, there was also a significant negative association between genes being up- or downregulated in reproductive workers and the tendency to be up- or downregulated in response to exposure to either QMP (test 30, Spearman rank correlation test, $p=0.02$, Table S2) or BP (test 33, Spearman rank correlation test, $p=0.04$, Table S2). This supports the role of QMP and $\mathrm{BP}$ in determining ovary activation in honeybee workers (Mohammedi et al. 1998; Hoover et al. 2003; Slessor et al. 2005; Maisonnasse et al. 2010). For examples see Figs 2 and 3 and Table S1.

\section{Functional enrichment analyses}

GO-term enrichment analysis demonstrated that 171 and 135 biological process GO-terms were significantly enriched among the genes which were upregulated in 
Name of gene

or fly ortholog BEEBASE FC $p_{\text {adj }}$ M QTL QMP BP ECD AS triglyceride lipase GB11256-RA $0.2 \quad 2.1 \mathrm{E}-0$. mily member 1 GB16799-RA $0.8 \quad 3.3 \mathrm{E}-03$ glycerol-3-phosphate dehydrogenase GB11613-RA $0.8 \quad$ 1.5E-02 lipophorin receptor GB16983-RA $0.8 \quad 2.0 \mathrm{E}-02$ $\mathrm{Z}$ band alt. spliced PDZ-motif protein 66 GB10901-RA $0.5 \quad 2.4 \mathrm{E}-0$ xylulokinase GB18997-RA $0.8 \quad 1.4 \mathrm{E}-02$ ADP-dependent glucokinase GB13862-RA $0.8 \quad 1.1 \mathrm{E}-02$ glucose-6-phosphate isomerase GB16429-RA 0.9 3.0E-02 enolase GB15039-RA $0.9 \quad 4.7 \mathrm{E}-02$ Citrate synhase GB12573 RA 0.8 8.0E-03 a aconita hydratase GB258 isocitrate dehydrogenase GB15716-RA $0.8 \quad 4.6 \mathrm{E}-03$ dihydrolipoamide succinyltransferase GB13073-RA $0.8 \quad 8.6 \mathrm{E}-03$ succinate dehydrogenase A GB17439-RA $0.8 \quad 1.0 \mathrm{E}-04$ cyto $V$-ATPase subunit I GB11830-RA 0.9 1.5E-02 -ATP se subunit 7 GB11840-RA 0.9 1.1.02 02

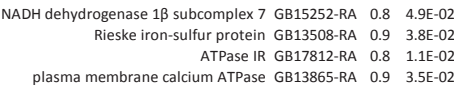

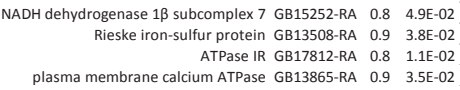
$\begin{array}{rrrr}\text { NADH dehydrogenase } 1 \beta \text { subcomplex } 7 & \text { GB15252-RA } & 0.8 & 4.9 \mathrm{E}-02 \\ \text { Rieske iron-sulfur protein } & \text { GB13508-RA } & 0.9 & 3.8 \mathrm{E}-02 \\ \text { ATPase IR } & \text { GB17812-RA } & 0.8 & 1.1 \mathrm{E}-02 \\ \text { plasma membrane calcium ATPase GB13865-RA } & 0.9 & 3.5 \mathrm{E}-02\end{array}$ $\mathrm{Na} / \mathrm{K}$-transporting ATPase subunit $\alpha$ GB20055-RA $0.7 \quad 5.1 \mathrm{E}-03$

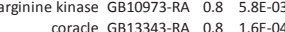
krotzkopf verkehrt GB12511-RA 0.8 6.5E-03 nitine transporter GB17795-RA $0.7 \quad 5.7 \mathrm{E}-03$ $\begin{array}{rll}\alpha \text {-glucosidase GB30223-RA } & 0.7 & 1.9 \mathrm{E}-02 \\ \text { nose resistant to fluoxetine protein } 6 \text { GB16461-RA } & 0.8 & 1.2 \mathrm{E}-02\end{array}$ insulinase domain containing gene GB11385-RA $0.8 \quad 1.3 \mathrm{E}-02$ MAK10 homolog GB11992-RA $0.9 \quad 2.9 \mathrm{E}-02$ C. $\delta$ GB13673-RA 0.8 8.4E-03 shaker GB18814-RA $0.8 \quad 4.3 \mathrm{E}-04$ hyperkinetic GB10006-RA $0.8 \quad 1.5 \mathrm{E}-04$ wings up A GB17075-RA $0.8 \quad 2.2 \mathrm{E}-03$ myosin regulatory light chain 2 GB13399-RA $0.8 \quad 9.7 \mathrm{E}-03$

myosin heavy chain 1 GB11965-RA $0.8 \quad 3.9 \mathrm{E}-04$ $\alpha$-actinin GB11028-RA 0.9 3.8E-02

yanodine receptor GB15169-RA $0.8 \quad 4.4 \mathrm{E}-02$ tropomyosin 1 GB30512-RC $0.8 \quad 3.2 \mathrm{E}-03$ excitatory amino acid transporter 3 GB16911-RA $0.8 \quad 3.2 \mathrm{E}-02$ 1 GB15959-RA $0.9 \quad 4.6 \mathrm{E}-02$ shaker cognate b GB19350-RA 0.8 1.7E-02 netrin receptor unc5 GB14364-RA $0.6 \quad 4.6 \mathrm{E}-02$ cycle GB11309-RA $0.8 \quad 2.6 \mathrm{E}-02$ llowpoke GB17365-RA $0.9 \quad 1.3 \mathrm{E}-02$

$\begin{array}{ccc}\text { quiver GB15765-RA } & 0.8 & 3.2 \mathrm{E}-02 \\ \text { clock GB17107-RA } & 0.9 & 4.0 \mathrm{E}-02\end{array}$ beadex GB14109-RA $0.8 \quad 1.7 \mathrm{E}-02$ venom dipeptidylpeptidase IV GB14496-RA $0.7 \quad 1.2 \mathrm{E}-02$ obstractor d GB16370-RA $0.6 \quad 2.5 \mathrm{E}-02$ $\begin{array}{lll}\text { klarsicht GB30140-RA } & 0.7 & 9.2 \mathrm{E}-03\end{array}$ no receptor potential A2 GB14619-RA $0.7 \quad 1.0 \mathrm{E}-02$ arrestin 1 GB16006-RA $0.8 \quad 8.1 \mathrm{E}-03$

$G$ protein $\beta$ subunit 1 GB12662-RA $0.8 \quad 1.3 \mathrm{E}-02$ Tr. discs large 1 GB30138-RE $\quad 0.8$ 4.3E-02

$\begin{array}{rrrr}\text { discs large } 1 & \text { GB30138-RE } & 0.8 & 4.3 \mathrm{E}-02 \\ \text { cytochrome P450 305D1 GB11943-RA } & 0.5 & 1.2 \mathrm{E}-02\end{array}$

neurotransmitter transporter 5 GB18205-RA $0.8 \quad 4.0 \mathrm{E}-02$ ligand-gated chloride channel homolog 3 GB12078-RA $0.6 \quad 1.1 E-02$ CG9297-PA GB12536-RA $0.6 \quad 9.6 \mathrm{E}-03$ $\begin{array}{lll}\text { receptor } \alpha 2 \text { GB18518-RA } & 0.8 & 2.0 \mathrm{E}-02 \\ & 0.2\end{array}$

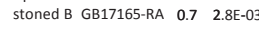
syaptotagmin 13 GB15417-RA $0.7 \quad 5.2 \mathrm{E}-03$

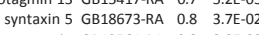
synapsin GB12564-RA $0.8 \quad 3.0 \mathrm{E}-02$ synaptotagmin 7 GB19709-RA $0.8 \quad 3.7 E-02$ synaptotagmin 4 GB11060-RA $0.8 \quad 2.7 \mathrm{E}-02$ capon GB10113-RA $0.8 \quad 2.6 \mathrm{E}-02$ bitesize GB13617-RA $0.9 \quad 2.6 \mathrm{E}-02$ molecule GB30209-RA 0.9 3.4E-02 cadherin-N GB12853-RB $0.8 \quad 6.4 \mathrm{E}-03$ unzipped GB14145-RA $0.8 \quad 1.8 \mathrm{E}-02$ chaoptic GB11660-RA $0.8 \quad 1.2 \mathrm{E}-02$ dynamin GB15728-RA $0.9 \quad 6.0 \mathrm{E}-03$

RAS GB15876-RA $0.8 \quad 3.4 \mathrm{E}-02$ calcium and integrin-binding protein 1 GB16769-RA $0.7 \quad 2.7 \mathrm{E}-02$ DNA-dep. protein kinase catalytic subunit GB11176-RA 0.8 3.4E-02

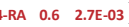
unnamed GB19325-RA $0.7 \quad 1.4 \mathrm{E}-02$ allatostatin GB30252-RA $0.7 \quad 3.0 \mathrm{EE}-03$ neuropeptide F GB16364-RA $0.8 \quad 4.5 \mathrm{E}-02$ MVPV neuropeptide GB19071-RB $0.8 \quad 2.6 \mathrm{E}-02$ prohormone 4 GB18206-RA $0.8 \quad 2.2 \mathrm{E}-02$ allatostatin A receptor GB19021-RA $0.8 \quad 4.5 \mathrm{E}-02$ orexin receptor type 2 GB19597-RA $0.7 \quad 3.2 \mathrm{E}-02$ diuretic hormone 44 receptor 1 GB10976-RA $0.8 \quad$ 1.9E-02 odorant receptor 156 GB30392-RA $0.5 \quad 8.1 \mathrm{E}-03$

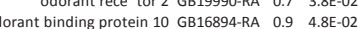
odorant binding $\begin{array}{rrrr}\text { sensory neuron membrane protein GB15549-RA } & 0.7 & 3.9 \mathrm{E}-02 \\ \text { cabut GB10114-RA } & 0.7 & 3.7 \mathrm{E}-02\end{array}$ $\begin{array}{ccc}\text { klingon GB10469-RA } & 0.8 & 7.5 \mathrm{E}-03\end{array}$ glycoprotein 150 GB10945-RA 0.8 8.9E-04 ecdysone-inducible gene L2 GB17369-RA 0.7 2.6E-02 anscription fuctor brica brac GB13762-RA 08 8.4E-03

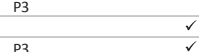

colony 1

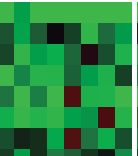

$\checkmark$

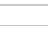

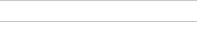

02
02

$+2$

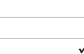

\section{P3} P2 $\checkmark$

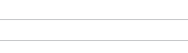

$+2$

P2
P2

$\checkmark$

$P 2$

$\llcorner 1$

\section{1}

$r$

$r$

$\checkmark$

$+$

03

$03 \quad r$

$\checkmark$

$\checkmark$
$x^{2}$

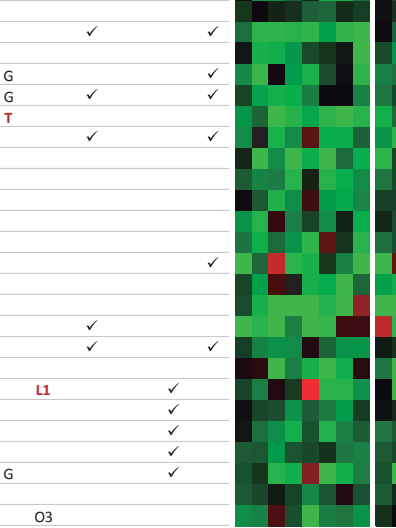

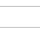

03

EXPR. RATIOS REPR/NONREPR W

colony 2 function

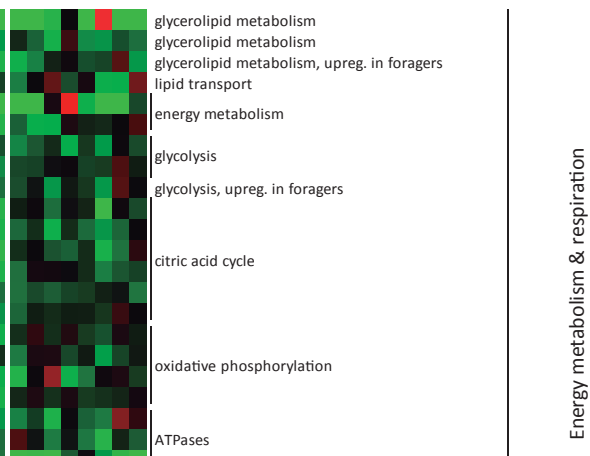

TP catabolism, upreg. in foragers

reg. of tube size, open tracheal system

reg. of tube diameter, open tracheal system

regulation of appetite

nectar processing in forager hypopharyngeal glands digestion, defecation

insulin breakdown

reg. of TOR sign. pathway, nutrient
neg. reg. of insulin sign. pathway

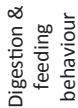

flight behaviour

\section{flight muscle contraction}

heart muscle contraction

heart muscle contraction

regulation of flight muscle contra

motor axon guidance

rhythmic behaviour, upreg. in foragers

rhythmic behaviour

aggression related, upreg. in foragers \& soldiers aggression related
venom protein venom protein
chitin biosynthesis chitin biosynthesis
detection of visible light

phototransduction

phototransduction

phototransduction

positive phototaxis

neurotransmitter transport

neurotransmitter transport

neurotransmission

neurotransmission

synaptic transmission

synaptic transmission, upreg. in soldiers

synaptic transmission

synaptic vesicle transport, upreg. in soldiers

axon extension involved in axon guidance

axon extension involved in axon guidance

axonogenesis, upreg. in foragers

memory

transcription factor

transcription factor, signal transduction

integrin-mediated signaling

serine/threonine protein kinase

ubiquitin-mediated proteolysis, endocytosis

unknown

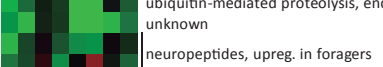

neuropeptides, upreg in nectar foragers

neuropeptide receptor, reg. JH synthesis

neuropeptide receptor, reg. JH synthesis
neuropeptide receptor, reg. JH synthesis \& feeding

neuropeptide receptor, reg. osmotic balance

odorant receptor

queen mandibular pheromone co-receptor

brain-specific odorant binding protein

response to pheromone

ecdysone-regulated ovary regression

ecdysone-regulated ovary regression
growth regulation, caste determination

growth regulation, caste deters
ovarian follicle cell migration

neg. reg. of insulin sign. pathway

neg. reg. of insulin sign.
germ band shortening

germ band shortening
female gonad development

\section{$\frac{\sqrt{2}}{\frac{n}{x}}$}


reproductive and nonreproductive workers, respectively (Tables 1 and S3, representative genes annotated with some of these GO-terms are shown in Figs 2 and 3).

Genes upregulated in reproductive workers were mostly enriched for GO-terms relating to oogenesis, mitosis, meiosis and the cell cycle (c. one-third of all enriched GO-terms). For examples see Fig. 3 and Table S1. Genes annotated with GO-terms concerning mRNA production, processing and turn-over which is necessary for the storage of maternal mRNA in mature oocytes, as well as genes annotated with GO-terms related to epigenetic control of gene expression (e.g. histone demethylation and acetylation), including, most notably, DNA methyltransferase 3 (Fig. 3 and Table S3) were also overrepresented. The latter might hint at the presence of germline DNA methylation and genomic imprinting (Queller 2003; Kucharski et al. 2008; Elango et al. 2009). For examples see Figs 2 and 3 and Table S1.

Among the genes upregulated in nonreproductive workers, genes annotated with GO-terms related to increased energy metabolism and respiration were greatly overrepresented, including for example six genes involved in the citric acid cycle, 10 genes involved in oxidative phosphorylation, several genes involved in glycolysis and ATP metabolic processes. Additional enriched terms are lipid transport and metabolism with differentially expressed genes such as triglyceride lipase, which was fivefold upregulated and is important for burning triglycerides (Canavoso et al. 2001) and the lipophorin receptor, which is involved in shuttling lipids out of the fat body, and which has previously been shown to be upregulated in the fat body and other tissues of nonreproductive honeybee workers (Guidugli-Lazzarini et al. 2008) (Tables 1 and S3, Fig. 2). In addition, genes involved in flight, foraging and locomotory behaviour, phototransduction, the detection of visible light, positive phototaxis and flight and heart muscle contraction were overexpressed in sterile workers, as well as genes involved in the regulation of the tracheal system (Tables 1 and S3, examples shown in Fig. 2). With respect to brain and neuron functioning, nonreproductive workers overexpressed genes involved in synaptic transmission, neurotransmitter transport, axon extension, memory and response to external stimuli and pheromones (Tables 1 and S3, Fig. 2). Lastly, the genes upregulated genes in sterile workers were also greatly, c. eightfold, enriched for neuropeptide precursors known to be associated with foraging behaviour or the modulation thereof (test 36, Fisher exact test, $p=0.004$, Table S2, Fig. 2).

\section{Overlap with QTL studies}

Genes that were upregulated in reproductive workers were 1.6-fold enriched within QTL OvA3, a region known to be associated with differences in worker reproductive behaviour (Oxley et al. 2008; Linksvayer et al. 2009) (test 43, Fisher exact test, $p=0.02$, Table S2), which was previously shown to be linked with variation in worker egg-laying in strains of anarchistic bees (Oxley et al. 2008). This association came about despite the fact that OvA3 was not significantly enriched for genes with oogenesis-related GO-terms (test 73, Fisher exact test, Table S2). Genes upregulated in nonreproductive workers, in turn, were significantly enriched for genes lying within QTL regions Pln1 to Pln4 (test 71, Fisher exact test, $p=0.03$, Table S2), which is known to be associated with differences in foraging predisposition and sucrose responsiveness (Hunt et al. 2007). Particularly the $c$. twofold, enrichment for genes lying within QTL Pln2 on chromosome 1 (test 59, Fisher exact test, $p=0.03$, Table S2) is noteworthy. There were no significant associations between our complete set of differentially expressed genes and any of the analysed QTLs (Table S2).

\section{Discussion}

Overall, our study revealed that there were significant differences in gene expression between reproductive and nonreproductive workers in a vast number (1292)

\footnotetext{
Fig. 2 Selection of genes which were upregulated in sterile workers, illustrating genes corresponding to enriched classes of GO BP terms (Tables 1 and S2) and genes of special interest. Beebase identifiers, putative function, fold change (FC, reproductive/nonreproductive) and $F D R$-adjusted $p$ values ( $p_{\text {adj }}$ ) are also mentioned, as well as whether the genes were confirmed to be upregulated in sterile workers in other microarray studies (M: $\mathrm{G}=$ upregulated in the brains of sterile workers in Grozinger et al. 2007), $\mathrm{T}=$ upregulated in wild-type vs. anarchistic workers in the studies of (Thompson et al. 2006, 2008)), mapped to QTL loci linked to worker reproductive potential and foraging predisposition (O1-O4: QTLs linked to the anarchy phenotype, Oxley et al. 2008; L1-L2: QTLs linked to variation in worker ovariole numbers, Linksvayer et al. 2009; P1-P4: QTLs linked to pollen foraging and sucrose responsiveness, Hunt et al. 2007), were known to be upregulated by exposure to queen mandibular pheromone (QMP, Grozinger et al. 2003) or brood pheromone (BP, Alaux et al. 2009a) and whether the gene's fly ortholog was known to be 20-hydroxyecdysone (20E)-responsive (ECD, Beckstead et al. 2005). We also mention genes which are differentially expressed between virgin queens, mated queens and laying queens (K, Kocher et al. 2008). Top-20 differentially expressed genes are highlighted in red. The 8 arrays performed per colony are arranged on the $\mathrm{X}$-axis based on a hierarchical clustering (tree not shown).
} 
8 D. CARDOEN ET AL.

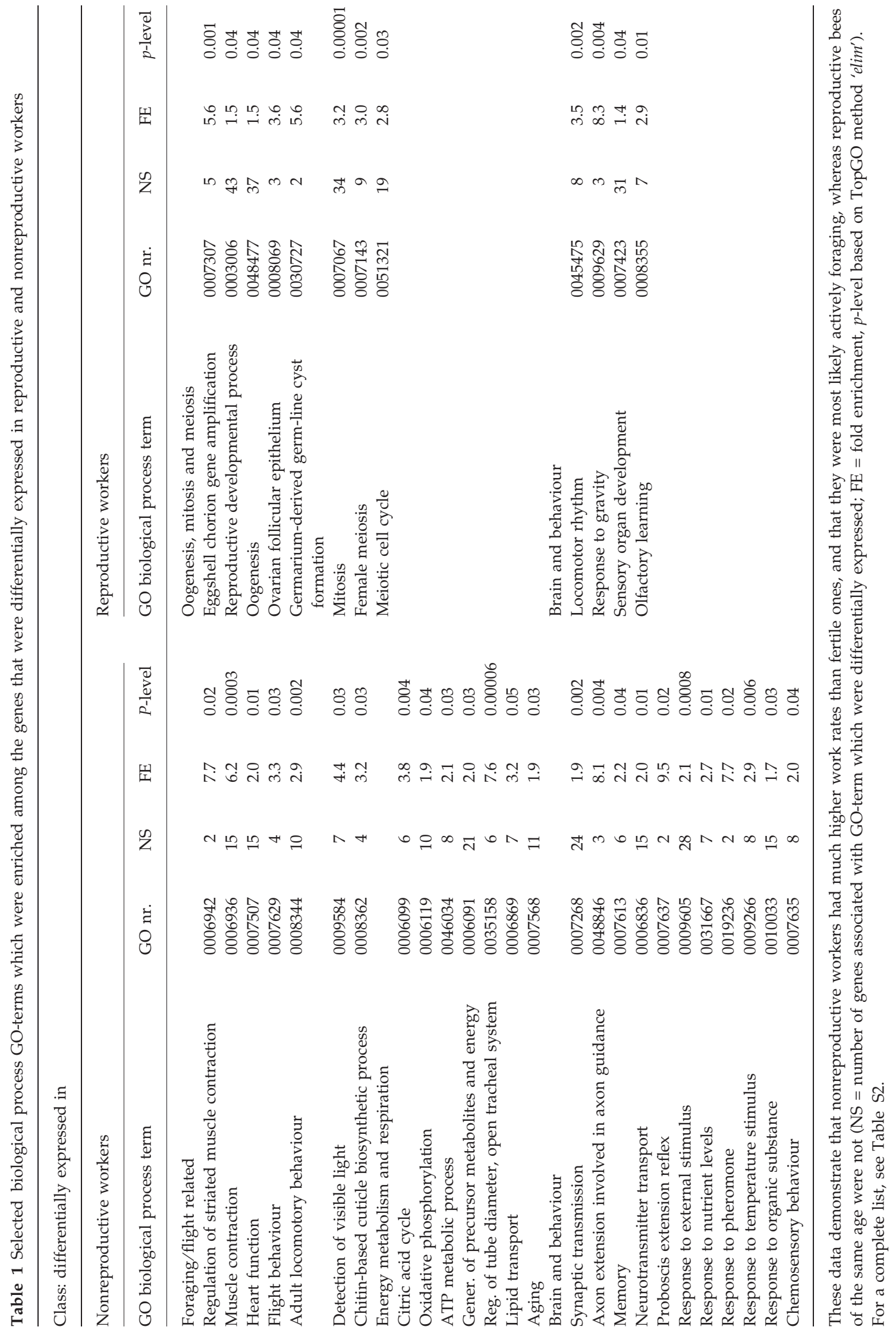


of genes, and together with the various enrichment analyses that we presented, this provides detailed insight into the physiology of both sets of workers. Below we discuss the implications of some of the associations that we found, and point out particular candidate genes which would deserve further study.

\section{Differential activity patterns of reproductive and nonreproductive workers}

Overall, the outcome of the GO enrichment analysis suggests that reproductive and nonreproductive workers greatly differed not only in their reproductive potential, but also in their generic activity patterns. In particular, in nonreproductive workers, genes associated with increased energy metabolism and respiration, flight and foraging behaviour, detection of visible light, flight and heart muscle contraction and synaptic transmission were all overexpressed, implying they probably had a higher whole-body energy metabolism and activity rate and were most likely already actively foraging, whereas same-aged reproductive workers were not. In addition, some of the differences we found are characteristic for the neural remodelling that occurs upon the transition from in-hive to outside tasks (Whitfield et al. 2003, 2006). In fact, several of the genes involved in these functions, including synaptotagmin 4 (regulating neurotransmitter release), bitesize (involved in eye and muscle development) and unzipped (involved in axon guidance), have all been shown to be overexpressed in brains of honeybee worker engaging in defensive behaviour (Alaux et al. 2009b), and, in the case of unzipped, also in brains of paper wasps (Toth et al. 2010). As additional evidence, however indirect, a venom gland protein (dipeptidylpeptidase IV) and bea$d e x$, an aggression-related gene previously shown to be upregulated in foragers and soldiers (Alaux et al. 2009b) are also upregulated in nonreproductive workers and hint to forage or defence tasks. Also a gene involved in motor axon guidance (netrin receptor unc5) for muscle coordination, 4 genes involved in the regulation of circadian rhythmic behaviour (including cycle and slowpoke, which both have been shown to be upregulated in foragers, Alaux et al. 2009a; Toth et al. 2010) were all upregulated in nonreproductive workers and are typical for foragers (Fig. 2). Additional experiments on dissected neural tissue will provide additional insights. Finally, genes related to digestion and feeding behaviour were also upregulated in nonreproductive workers, for example $\alpha$-glucosidase, which is one of only five proteins with a function in carbohydrate metabolism known to be expressed in the hypopharyngeal glands of worker bees (Santos et al. 2005; Alaux et al. 2009b), and thought to be involved in the process- ing of nectar by forager bees (Kubo et al. 1996; Wolschin \& Amdam 2007; Alaux et al. 2009b). Taken together, it therefore seems likely that nonreproductive workers had higher metabolic and implied activity rates, and were most likely actively foraging, whereas same-aged reproductive workers were not. This clearly supports our hypothesis that reproductive workers should tend to avoid carrying out risky tasks, so as to not compromise their reproductive futures (Franks \& Scovell 1983; Bourke 1988), and is in line with earlier behavioural studies that have documented reduced work rates and an earlier onset of foraging in honeybee strains with a high reproductive potential (Hillesheim et al. 1989; Martin et al. 2002; Dampney et al. 2004; Oldroyd \& Beekman 2008).

\section{Overexpression of foraging-related neuropeptides in nonreproductive workers}

In further support of nonreproductive workers having a greater foraging predisposition, we also found that genes upregulated in nonreproductive workers were greatly, $c$. eightfold, enriched for neuropeptide precursors known to be associated with foraging behaviour or the modulation thereof (test 36, $p=0.004$, Table S2). In particular, sterile workers overexpressed the 4 neuropeptide encoding transcripts: allatostatin, neuropeptide F, MVPV neuropeptide and prohormone 4 (Fig. 2). Allatostatin, which in several insects is known to inhibit $\mathrm{JH}$ production in the corpora allata, is upregulated in foragers in both the honeybee (Alaux et al. 2009a) and in paper wasps (Toth et al. 2010). Neuropeptide F has been identified as one of the 100 genes most predictive for honeybee foraging (Alaux et al. 2009a). Finally, MVPV neuropeptide and prohormone 4 have both been shown to be associated with nectar rather than pollen foraging (Brockmann et al. 2009) and the latter has also been shown to be upregulated in foragers relative to nurses (Whitfield et al. 2003). In addition to the aforementioned neuropeptide precursors, nonreproductive workers also overexpressed 3 neuropeptide receptors: diuretic hormone 44 receptor 1 , the allatostatin A receptor and the allatotropin receptor (Weaver \& Audsley 2009), as well as the nuclear receptor and transcription factor $f t z-f 1$. The allatostatin and allatotropin receptors are known to regulate $\mathrm{JH}$ synthesis and may be implicated in the marked change in the $\mathrm{JH}$ hemolymph titres seen upon the transition from in-hive to outside tasks (Robinson \& Vargo 1997; Robinson \& Huang 1998). Ftz-f1 may be implicated in ecdysone-regulated ovary regression in nonreproductive workers, given that it has previously been shown to be important in honeybee caste determination and that its expression has been shown to be repressed by exposure to ecdysteroids (Hepperle \& Hartfelder 2001). 
Name of gene

or fly ortholog BEEBASE FC $p_{\text {adj }}$ M QTL QMP BP ECD K

transcription factor E2F GB18882-RA $6.8 \quad 7.9 \mathrm{E}-09$ maintenance 6 GB19871-RA $2.2 \quad 3.1 \mathrm{E}-03$ myb protein GB12498-RA $1.8 \quad 2.0 \mathrm{E}-05$ transcription factor DF GB13495-RA $1.5 \quad 3.0 E-05$ myb-interacting protein 120 GB10684-RA $1.8 \quad 1.8 \mathrm{E}-03$ double parked GB12839-RA $1.6 \quad 5.3 \mathrm{E}-05$ piefke GB15091-RA $1.2 \quad 3.5 \mathrm{E}-02$ single-minded GB11417-RA $2.2 \quad 1.8 \mathrm{E}-03$ huckebein GB30303-RA 19.2 3.3E-06

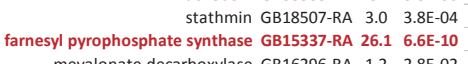
mevalonate decarboxylase GB16296-RA $1.2 \quad 2.8 \mathrm{E}-02$ cholesterol O-acyltransferase GB16016-RA $\quad 1.5 \quad 3.0 \mathrm{E}-03$ without children GB19476-RA $1.2 \quad 9.2 \mathrm{E}-03$

cytochrome P450 314A1 GB13998-RA $3.8 \quad 7.8 \mathrm{E}-06$ fringe glycosyltransferase GB17604-RA $\quad \begin{array}{llll}1.7 & 3.7 \mathrm{E}-02\end{array}$ cbl GB16551-RA $1.4 \quad 2.5 \mathrm{E}-0$ slimfast GB15921-RA $1.4 \quad 7.3 \mathrm{E}-03$ tuberous sclerosis complex 1 GB12676-RA $1.3 \quad 5.9 \mathrm{E}-05$ tyrosine phosphatase 61F GB14529-RA $1.2 \quad 3.1 \mathrm{E}-02$ shaggy GB30241-RB $1.2 \quad 2.5 \mathrm{E}-02$ FAM47C GB19763-RA $28.4 \quad$ 1.3E-04 DNA methyltransferase 3 GB14232-RA $2.1 \quad 2.1 \mathrm{E}-06$ homeobox protein six4 GB10752-RA $3.8 \quad$ 1.4E-04 immunoglobulin CG42343 GB12833-RA $2.7 \quad 3.9 \mathrm{E}-04$ G2/mitotic-specific cyclin-A GB14847-RA $9.1 \quad 5.9 E-07$ kinesin 8 GB10037-RA 15.6 1.4E-09 chromator GB10259-RA $1.2 \quad 9.5 \mathrm{E}-04$ t-complex chaperonin 5 GB10587-RA $1.2 \quad 3.2 \mathrm{E}-03$ $\begin{array}{ccc}\text { decapping protein } 1 \text { GB14691-RA } & 2.3 & 4.3 \mathrm{E}-05 \\ \end{array}$ maelstrom GB17844-RA $14.3 \quad 2.1 \mathrm{E}-07$ vasa GB14804-RA $6.1 \quad 2.3 \mathrm{E}-02$

oo18 RNA-binding protein GB12560-RB $5.1 \quad 7.0 \mathrm{E}-08$ $\begin{array}{lll}\text { exuperantia GB19360-RA } & 2.1 & 3.3 \mathrm{E}-02\end{array}$ kinesin A GB18655-RA $7.9 \quad 2.0 \mathrm{E}-09$ $\begin{array}{rrrr}\text { serine/threonine protein kinase } 6 \text { (aurora) GB14418-RA } & 5.4 & 2.1 \mathrm{E}-07 \\ \text { kinesin 14 GB13977-RA } & 3.8 & 1.9 \mathrm{E}-05\end{array}$ $\begin{array}{rrrr}\text { serine/threonine protein kinase } 6 \text { (aurora) GB14418-RA } & 5.4 & 2.1 \mathrm{E}-07 \\ \text { kinesin 14 GB13977-RA } & 3.8 & 1.9 \mathrm{E}-05\end{array}$ \begin{tabular}{ccc} 
& \\
bifocal 1 GB18839-RA & 2.1 & $3.6 \mathrm{E}-03$ \\
\hline
\end{tabular} mini spindles GB10660-RA $1.5 \quad 2.4 \mathrm{E}-02$

targeting protein for XkIp2 GB14990-RA $15.6 \quad 1.4 \mathrm{E}-09$ serine/threonine protein kinase JIL-1 GB13245-RA $1.4 \quad 9.3 \mathrm{E}-03$ germinal histone H4 GB14107-RA $10.3 \quad 3.8 \mathrm{E}-07$ chromatin assembly foctor 1 SUbunit A GB15706-RA 19.9 28.07 yellow-g GB10842-RA $25.7 \quad 8.8 \mathrm{E}-05$

$$
\begin{array}{rrr}
\text { hoepel1 GB14978-RA } & 22.1 & 2.6 \mathrm{E}-08 \\
\text { drop dead GB15247-RA } & 4.3 & 1.7 \mathrm{E}-04 \\
\text { phosphatase GB11379-RA } & 2.7 & 7.3 \mathrm{E}-07
\end{array}
$$
star GB13389-RA $2.7 \quad 5.7 \mathrm{E}-06$ eggless GB17661-RA $2.0 \quad 8.1 \mathrm{E}-07$ p83/Hsp90) GB14494-RA $1.8 \quad 1.4 \mathrm{E}-02$ ovo protein GB11352-RA $1.6 \quad 6.7 \mathrm{E}-06$ DNA topoisomerase 1 GB15849-RA $1.5 \quad 1.8 \mathrm{E}-04$ domino GB10524-RB $1.4 \quad 1.4 \mathrm{E}-02$ domino GB10524-RB $1.4 \quad 1.4 \mathrm{E}-02$ $\begin{array}{lll}\text { brain tumor GB12558-RA } & 2.1 & 1.5 \mathrm{E}-03 \\ \text { ted gene E74 GB10759-RA } & 1.2 & 4.0 \mathrm{E}-02\end{array}$ $\begin{array}{rrr}\text { ecdysteroid-regulated gene E74 GB10759-RA } & 1.2 & 4.0 \mathrm{E}-02 \\ \text { broad-complex GB14070-RA } & 1.2 & 4.7 \mathrm{E}-02 \\ \text { dacapo GB12878-RA } & 2.6 & 1.2 \mathrm{E}-04 \\ \text { Srcon }\end{array}$ $\begin{array}{rrr}\text { ecdysteroid-regulated gene E74 GB10759-RA } & 1.2 & 4.0 \mathrm{E}-02 \\ \text { broad-complex GB14070-RA } & 1.2 & 4.7 \mathrm{E}-02 \\ \text { dacapo GB12878-RA } & 2.6 & 1.2 \mathrm{E}-04 \\ \text { Srcon }\end{array}$ Src oncogene at $64 \mathrm{~B}$ ortholog GB14772-RA $1.8 \quad 8.8 \mathrm{E}-06$ poly A binding protein cytoplasmic 1 GB11055-RA 1.2 3.8E-02 $\begin{array}{lll}\text { protein on ecdysone puffs GB13256-RA } & 1.5 & 1.8 \mathrm{E}-04\end{array}$ megator GB11086-RA $1.6 \quad 6.0 \mathrm{E}-06$ \begin{tabular}{lll} 
odorant binding protein 9 GB13938-RA $5.0 \quad 4.3 \mathrm{E}-05$ \\
\hline
\end{tabular} odorant binding protein 7 GB30243-RA $2.4 \quad$ 1.0E-02 squid GB12840-RA $1.3 \quad 1.6 \mathrm{E}-03$ ecdysone 20-monooxygenase GB30218-RA $4.2 \quad 3.2 \mathrm{E}-06$ supernumerary limbs GB10096-RA $\quad 1.5 \quad 1.1 \mathrm{E}-04$ $\begin{array}{lll}\text { buffy GB15274-RA } & 5.6 & 3.3 \mathrm{E}-08\end{array}$ heat shock protein DnaJ (Hsp40) GB19172-RA $1.3 \quad 1.2 \mathrm{E}-03$ lipid storage droplet-1 GB15498-RA $1.7 \quad 6.4 \mathrm{E}-04$ wech GB19249-RA $68.5 \quad 2.0 \mathrm{E}-08$ vitellogenin GB13999-RA $1.9 \quad 2.6 \mathrm{E}-01 \quad \mathrm{G}$, yolkless GB16571-RA $6.5 \quad 2.8 \mathrm{E}-06$ a-methyldopa hypersensitive protein GB30066-RA $1.8 \quad 9.8 \mathrm{E}-03$ ecdysteroid-regulated gene E93/mblk-1 GB16065-RA 26.5 8.0E-05 gustatory receptor 3 GB16407-RA $2.1 \quad 1.5 \mathrm{E}-03$ $\begin{array}{llll}\text { defective proboscis extension response GB16778-RA } & 1.3 & 2.7 \mathrm{E}-02\end{array}$ pteropsin GB12200-RA $1.7 \quad$ 4.0E-02 PDF receptor GB14562-RA $1.6 \quad 2.4 \mathrm{E}-03$ estrogen-related receptor GB11125-RA $1.3 \quad 1.1 \mathrm{E}-03$ $\begin{array}{lll}\text { estrogen-related receptor GB11125-RA } & 1.3 & 1.1 \mathrm{E}-03 \\ \end{array}$ $\begin{array}{rrrr}\text { ETHR ecdysis-triggering hormone receptor GB13260-RA } & 1.5 & 4.7 \mathrm{E}-02 \\ \text { prohormone 2 } & \text { GB10356-RA } & 1.2 & 1.1 \mathrm{E}-02 \\ \text { metabotropic GABA-B receptor subtype 2 GB13604-RA } & 1.4 & 5.4 \mathrm{E}-04\end{array}$ $\begin{array}{rrrr}\text { metabotropic GABA-B receptor subtype } 2 & \text { GB13604-RA } & 1.4 & 5.4 \mathrm{E}-04 \\ \text { unnamed GB10975-RA } & 2.4 & 4.0 \mathrm{E}-04\end{array}$

$\begin{array}{rrr}\text { unnamed GB10975-RA } & 2.4 & 4.0 \mathrm{E}-04 \\ \text { upstream of N-ras GB11497-RA } & 1.5 & 6.2 \mathrm{E}-06\end{array}$

TATA-box-binding protein GB17946-RA $1.4 \quad 8.2 \mathrm{E}-06$ unnamed GB16814-RA $8.3 \quad 3.2 E-06$ FAM60A GB18347-RA $1.3 \quad 1.6 \mathrm{E}-02 \quad \mathrm{G}$

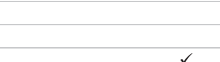

Putative
function

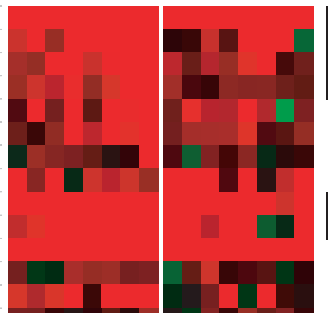

03

$r \quad r$

03

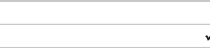

G

O3

$\checkmark$

L2

04

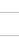

\section{G}

$+2$

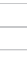

L1

$\begin{array}{cl}\mathrm{L} 1 & \\ & \checkmark\end{array}$

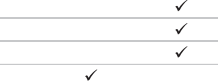

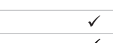

01

01

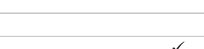

G

$G, T$

$+2$

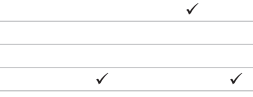

03

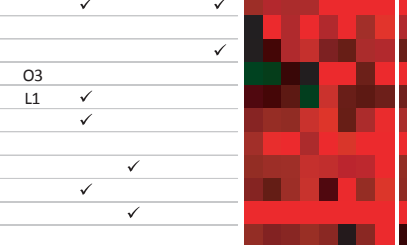

EXPR. RATIOS REPR/NONREPR W

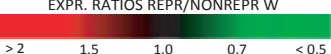

eggshell chorion gene amplification

eggshell chorion gene amplification

chorion gene amplification, regulation of oviposition female gonad development genital disc development

germ cell migration

germ cell migration, steroid biosynthesis steroid biosynthesis

steroid biosynthesis

ecdysteroid biosynthesis

egg chamber growth, $20 \mathrm{E}$ biosynthesis

egg chamber formation

germ line cyst formation, reg. insulin sign. pathway

lipid metabolism, growth regulation

reg. TOR \& insulin sign. pathways

reg. of insulin sign. pathway

follicle cell development, reg. insulin sign. pathway germ line protein

de novo DNA methylation, germ line imprinting

gonad development

mitotic cell cycle

mitotic spindle organisation

mitotic spindle organisation

nurse cell to oocyte transport

oocyte axis specification

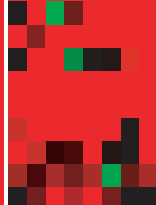

oocyte meiosis

oocyte meiosis

oocyte meiosis

oocyte nucleosome assembly

nucleosome assembly, DNA replication

nucleoso

oogenesis

genesis

oogenesis

oogenesis

oogenesis, caste determination

ovarian odorant binding proteins

ovarian follicle cell migration

ovarian follicle cell development, $20 \mathrm{E}$ biosynthesis ovarian follicle cell development

ovarian follicle development

protein folding

lipid transport \& storage

ovary muscle functionin

yolk protein precursor

vitellogenin receptor, vitellogenin transport

dopamine sensitive protein

mushroom body-specific transcription factor

gustatory receptor

proboscis extension reflex

nonvisual opsin
circadian rhythm

circadian rhythm

neuropeptide receptor

neuropeptide

neurotransmission

transcription factor

transcription factor

transcription factor

cysteine peptidase

unknown 
By contrast, only one neuropeptide precursor, the Apis-specific prohormone 2 (Fig. 3), was upregulated in reproductive workers. It is not known to modulate foraging behaviour (Brockmann et al. 2009) but has been shown to be downregulated by exposure to QMP (Grozinger et al. 2003), which may suggest a role in the regulation of reproduction. Finally, in reproductive workers not only the orphan nuclear oestrogen-related receptor $\alpha$, which is an upstream factor of vitellogenin synthesis, was upregulated, but also the gene for ecdysis-triggering hormone (ETH) receptor, suggesting an additional function for the latter. The ETH receptor was recently found to be expressed in the corpora allata in Bombyx mori, pointing to a role in the regulation of $\mathrm{JH}$ synthesis (Yamanaka et al. 2008).

\section{Genes lying within QTLs linked to worker reproductive potential and foraging predisposition}

The overlap with QTLs associated with increased reproductive potential offers a useful approach to identify candidate genes linked to worker reproduction. It enables a targeted approach to reconstruct the genetic architecture of candidate genes, which are potentially cis-regulated. Candidate genes contained within the QTLs include $m y b$, a transcription factor that regulates eggshell chorion formation, double parked, involved in the regulation of oviposition, piefke, involved in female gonad development and mevalonate decarboxylase, which is involved in steroid biosynthesis (Fig. 3). Additional genes of interest are slimfast, involved in the regulation of growth and the TOR signalling pathway, which is involved in queenworker caste determination (Wheeler et al. 2006; Corona et al. 2007; Patel et al. 2007; de Azevedo \& Hartfelder 2008), and the gene coding for ecdysis-triggering hormone receptor (Fig. 3).

Similarly, we also found genes upregulated in nonreproductive workers to be enriched for genes lying within the foraging-related QTLs Pln 1-4 (Table S2; Hunt et al. 2007). Candidate genes that might explain this association include tropomyosin 1, involved in heart muscle contraction, quiver, involved in rhythmic behaviour, an organic cation/carnitine transporter, involved in the regulation of appetite, nose resistant to fluoxetine protein 6, involved in digestion and defecation, an insulinase domain containing gene (insulin breakdown) and MAK10 homolog (regulation of the TOR signalling pathway and nutrient sensing) (Fig. 2).

\section{Additional candidate genes linked to worker ovary activation}

With respect to key switches involved in the activation of ovary development in reproductive workers, several genes involved in steroid biosynthesis were upregulated in reproductive workers. This includes one of the seven known copies of farnesyl pyrophosphate synthase (The Honeybee Genome Sequencing Consortium 2006), which was 26-fold upregulated, as well as cholesterol O-acyltransferase, without children, cytochrome P450 314A1 and ecdysone 20-monooxygenase (Fig. 3, Table S1). Many genes that were ecdysteroid-induced were also upregulated, including the brain expressed ecdysteroid-regulated gene E93/mblk-1 (Park et al. 2003), which was 27-fold upregulated and has previously been inferred to be important in the detection of QMP and shown to correlate with worker ovary size (Kocher et al. 2010), ecdysteroid-regulated gene E74, broad-complex, lipid storage droplet-1, and several others (Fig. 3). A dopamine-responsive gene, $\alpha$-methyldopa hypersensitive protein is noteworthy as well. As expected, given the involvement of these pathways in, among others, honeybee caste determination, components of the TOR and insulin signalling pathways were upregulated, including $c b l$, the QMP downregulated gene slimfast, tuberous sclerosis complex 1, tyrosine phosphatase 61F and shaggy (Fig. 3) (Wheeler et al. 2006; Corona et al. 2007; Patel et al. 2007; de Azevedo \& Hartfelder 2008). Furthermore, megator was upregulated in reproductive workers, which is also known to be involved in honeybee caste determination (Barchuk

\footnotetext{
Fig. 3 Selection of genes which were upregulated in reproductive workers, illustrating genes corresponding to enriched classes of GO BP terms (Tables 1 and S2) and genes of special interest. Beebase identifiers, putative function, fold change upregulation in reproductive workers $(\mathrm{FC})$ and $F D R$-adjusted $p$ values $\left(p_{\text {adj }}\right)$ are also mentioned, as well as whether the genes were confirmed to be upregulated in reproductive workers in other microarray studies (M: $\mathrm{G}=$ upregulated in the brains of reproductive workers in Grozinger et al. 2007), $\mathrm{T}$ = upregulated in wild-type vs. anarchistic workers in the studies of Thompson et al. (2006, 2008)), mapped to QTL loci known be linked to worker reproductive potential and foraging predisposition (O1-O4: QTLs linked to the anarchy phenotype, Oxley et al. 2008; L1-L2: QTLs linked to variation in worker ovariole numbers, Linksvayer et al. 2009; P1-P4: QTLs linked to pollen foraging and sucrose responsiveness, Hunt et al. 2007), were known to be downregulated by exposure to queen mandibular pheromone (QMP, Grozinger et al. 2003) or brood pheromone (BP, Alaux et al. 2009a) and whether the gene's fly ortholog was known to be 20-hydroxyecdysone (20E)-responsive (ECD, Beckstead et al. 2005). We also mention genes which are differentially expressed between virgin queens, mated queens and laying queens (K, Kocher et al. 2008). Top-20 differentially expressed genes are highlighted in red. The 8 arrays performed per colony are arranged on the X-axis based on a hierarchical clustering (tree not shown).
} 
et al. 2007) and downregulated by exposure to QMP (Grozinger et al. 2007) needs mentioning. Interestingly, vitellogenin was differentially expressed in only one of the two colonies (in colony 1: $p_{\text {adj }}=0.035$, but not in colony 2: $p_{\text {adj }}=0.83$ ). Nevertheless, the vitellogenin receptor yolkless, which is involved in the transport of vitellogenin into the developing ovary (Guidugli-Lazzarini et al. 2008), was sixfold upregulated in reproductive workers of both colonies (Fig. 3).

\section{Additional candidate genes linked to worker sterility}

Although genes related to differences in metabolism and in worker ovary activation represent the vast majority of differentially expressed genes in our study, we also found several genes which are potential key determinants in controlling worker reproduction at an early stage in the gene regulatory pathway (Figs 2 and 3). For example, A. mellifera odorant receptor 2 (Fig. 3) was significantly upregulated in nonreproductive workers and has previously been shown to be a queen pheromone co-receptor (together with AmOr11, Wanner et al. 2007), and known to be upregulated by exposure to QMP (Grozinger et al. 2007). This suggests that workers that are more sensitive to QMP may also be less likely to activate their ovaries when the colony becomes queenless. Similarly, odorant receptor 156, which was 2.1-fold upregulated in nonreproductive workers, and odorant binding protein 10 (obp10), which is known to be upregulated by exposure to QMP (Grozinger et al. 2007), might be implicated in the response to queen or brood pheromone and the regulation of worker reproduction.

Ecdysteroid-regulated genes upregulated in nonreproductive workers represent another interesting class of genes which might represent key switches in inducing worker sterility, for example cabut, involved in germ band shortening and associated with a QTL locus that has been shown to be linked with variation in worker ovariole numbers (Linksvayer et al. 2009) and the aforementioned orphan nuclear receptor ftz-f1 as well as Klingon, involved in honeybee caste determination (Hepperle \& Hartfelder 2001; Guidugli et al. 2004). Furthermore, ecdysone-inducible gene L2, which negatively regulates the insulin signalling pathway and the inwardly rectifying $\mathrm{K}^{+}$-channel, involved in germ band shortening is upregulated in nonreproductive workers (Fig. 2, Table S1), which suggests functions of insulinlike peptides in repressing ovary activation. The transcription factor bric-a-brac, involved in female gonad development, may also represent a possible switch in maintaining sterility in nonreproductive workers (Fig. 2, Table S1).

\section{Conclusion}

Overall, our study revealed that there were massive differences between reproductive and nonreproductive workers in whole-body gene expression for 1292 out of $11062(12 \%)$ of the genes represented in the honeybee genome. This dataset provides unprecedented insight into the molecular players underlying alternative reproductive insect phenotypes. One surprising conclusion stemming from these data was that reproductive and nonreproductive workers not only differed in their reproductive potential, as shown by the differential expression of various oogenesis-related genes, but also in the expression of various genes that are related to differences in their likely activity patterns. This was shown by the fact that nonreproductive workers overexpressed genes involved in flight behaviour, muscle contraction, respiration, heartbeat, vision and phototaxis (Tables 1 and S3), as well as foraging-related neuropeptides and genes linked to foraging-related QTLs (Table S2). This finding supports the theoretical prediction stating that laying workers should be selected to exploit the colony by carrying out low-risk tasks, so as to not compromise their reproductive futures (Franks \& Scovell 1983; Bourke 1988), and is consistent with the somewhat reduced work rate (i.e. engagement in inhive tasks as well as in foraging and defence) and foraging predisposition of reproductive workers documented by direct behavioural observations in honeybee workers (Hillesheim et al. 1989; Dampney et al. 2004; Oldroyd \& Beekman 2008).

Even though our study was mainly aimed at documenting downstream gene expression changes that occur in reproductive vs. nonreproductive bees, we also discovered many candidate genes linked to the early steps of worker ovary activation. Future experiments on separate tissues can provide insights into the complete physiological pathways underlying worker sterility. Overall, this set of genes should provide a rich resource for future functional genomic studies, and should help towards the discovery of some of the key genetic determinants of the suppressed fertility of honeybee and other social insect workers.

\section{Acknowledgements}

DC and UE are supported by the Agency for Innovation by Science and Technology (IWT), PV is a postdoctoral fellow of the Research Foundation-Flanders (FWO). Research was funded by FWO-grant G041708N. We thank I. Timmermans for help with the validation experiment, G. Belcanto for support and reviewers for useful feedback. MicroArray hybridisations were performed by the VIB MicroArray Facility (http:// www.microarrays.be). 


\section{References}

Alaux C, Le Conte Y, Adams HA et al. (2009a) Regulation of brain gene expression in honey bees by brood pheromone. Genes, Brain and Behavior, 8, 309-319.

Alaux C, Sinha S, Hasadsri L et al. (2009b) Honey bee aggression supports a link between gene regulation and behavioral evolution. Proceedings of the National Academy of Sciences, USA, 106, 15400-15405.

Alexa A, Rahnenfuhrer J, Lengauer T (2006) Improved scoring of functional groups from gene expression data by decorrelating GO graph structure. Bioinformatics, 22, 16001607.

Amdam GV, Norberg K, Fondrk MK et al. (2004) Reproductive ground plan may mediate colony-level selection effects on individual foraging behavior in honey bees. Proceedings of the National Academy of Sciences, USA, 101, 11350-11355.

Amdam GV, Csondes A, Fondrk MK et al. (2006) Complex social behaviour derived from maternal reproductive traits. Nature, 439, 76-78.

de Azevedo SV, Hartfelder K (2008) The insulin signaling pathway in honey bee (Apis mellifera) caste developmentdifferential expression of insulin-like peptides and insulin receptors in queen and worker larvae. Journal of Insect Physiology, 54, 1064-1071.

Barchuk AR, Bitondi MMG, Simoes ZLP (2002) Effects of juvenile hormone and ecdysone on the timing of vitellogenin appearance in hemolymph of queen and worker pupae of Apis mellifera. Journal of Insect Science (Tucson), 2, 1-9.

Barchuk AR, Cristino AS, Kucharski R et al. (2007) Molecular determinants of caste differentiation in the highly eusocial honeybee Apis mellifera. BMC Developmental Biology, 7, 70.

Barron AB, Oldroyd BP, Ratnieks FLW (2001) Worker reproduction in honey-bees (Apis) and the anarchic syndrome: a review. Behavioral Ecology and Sociobiology, 50, 199-208.

Beckstead RB, Lam G, Thummel CS (2005) The genomic response to 20-hydroxyecdysone at the onset of Drosophila metamorphosis. Genome Biology, 6, R99.

Benjamini Y, Hochberg Y (1995) Controlling the false discovery rate- a practical and powerful approach to multiple testing. Journal of the Royal Statistical Society Series B, 57, 289-300.

Bloch G, Borst DW, Huang Z et al. (2000) Juvenile hormone titers, juvenile hormone biosynthesis, ovarian development and social environment in Bombus terrestris. Journal of Insect Physiology, 46, 47-57.

Boerjan B, Cardoen D, Bogaerts A et al. (2010) Mass spectrometric profiling of (neuro)-peptides in the worker honeybee, Apis mellifera. Neuropharmacology, 58, 248-258.

Bourke AFG (1988) Worker reproduction in the higher Eusocial hymenoptera. Quarterly Review of Biology, 63, 291-311.

Brito RM, McHale M, Oldroyd BP (2010) Expression of genes related to reproduction and pollen foraging in honey bees (Apis mellifera) narcotized with carbon dioxide. Insect Molecular Biology, 19, 451-461.

Brockmann A, Annangudi SP, Richmond TA et al. (2009) Quantitative peptidomics reveal brain peptide signatures of behavior. Proceedings of the National Academy of Sciences, USA, 106, 2383-2388.

Canavoso LE, Jouni ZE, Karnas KJ et al. (2001) Fat metabolism in insects. Annual Review of Nutrition, 21, 23-46.
Capella ICS, Hartfelder K (1998) Juvenile hormone effect on DNA synthesis and apoptosis in caste-specific differentiation of the larval honey bee (Apis mellifera L.) ovary. Journal of Insect Physiology, 44, 385-391.

Corona M, Velarde RA, Remolina S et al. (2007) Vitellogenin, juvenile hormone, insulin signaling, and queen honey bee longevity. Proceedings of the National Academy of Sciences, USA, 104, 7128-7133.

Dampney JR, Barron AB, Oldroyd BP (2004) Measuring the cost of worker reproduction in honeybees: work tempo in an 'anarchic' line. Apidologie, 35, 83-88.

Darwin C (1859) On the origin of species by means of natural selection, John Murray, London.

Elango N, Hunt BG, Goodisman MA et al. (2009) DNA methylation is widespread and associated with differential gene expression in castes of the honeybee, Apis mellifera. Proceedings of the National Academy of Sciences, USA, 106, 11206-11211.

Foret S, Maleszka R (2006) Function and evolution of a gene family encoding odorant binding-like proteins in a social insect, the honey bee (Apis mellifera). Genome Research, 16, 1404-1413.

Franks NR, Scovell E (1983) Dominance and reproductive success among slave-making worker ants. Nature, 304, 724725 .

Gotz S, Garcia-Gomez JM, Terol J et al. (2008) Highthroughput functional annotation and data mining with the Blast2GO suite. Nucleic Acids Research, 36, 3420-3435.

Grozinger CM, Sharabash NM, Whitfield CW et al. (2003) Pheromone-mediated gene expression in the honey bee brain. Proceedings of the National Academy of Sciences, USA, 100(Suppl. 2), 14519-14525.

Grozinger CM, Fan Y, Hoover SE et al. (2007) Genome-wide analysis reveals differences in brain gene expression patterns associated with caste and reproductive status in honey bees (Apis mellifera). Molecular Ecology, 16, 4837-4848.

Guidugli KR, Hepperle C, Hartfelder K (2004) A member of the short-chain dehydrogenase/reductase (SDR) superfamily is a target of the ecdysone response in honey bee (Apis mellifera) caste development. Apidologie, 35, 37-47.

Guidugli KR, Nascimento AM, Amdam GV et al. (2005) Vitellogenin regulates hormonal dynamics in the worker caste of a eusocial insect. FEBS Letters, 579, 4961-4965.

Guidugli-Lazzarini KR, do Nascimento AM, Tanaka ED et al. (2008) Expression analysis of putative vitellogenin and lipophorin receptors in honey bee (Apis mellifera L.) queens and workers. Journal of Insect Physiology, 54, 1138-1147.

Hamilton WD (1964b) Genetical evolution of social behaviour I \& II. Journal of Theoretical Biology, 7, 1-52.

Hartfelder K, Kostlin K, Hepperle C (1995) Ecdysteroiddependent protein-synthesis in caste-specific development of the larval honey-bee ovary. Rouxs Archives of Developmental Biology, 205, 73-80.

Hartfelder K, Bitondi MMG, Santana WC et al. (2002) Ecdysteroid titer and reproduction in queens and workers of the honey bee and of a stingless bee: loss of ecdysteroid function at increasing levels of sociality? Insect Biochemistry and Molecular Biology, 32, 211-216.

Hepperle C, Hartfelder K (2001) Differentially expressed regulatory genes in honey bee caste development. Naturwissenschaften, 88, 113-116. 
Hillesheim E, Koeniger N, Moritz RFA (1989) Colony performance in honeybees (Apis mellifera mapensis Esch) depends on the proportion of subordinate and dominant Workers. Behavioral Ecology and Sociobiology, 24, 291-296.

Hoover SER, Keeling CI, Winston ML et al. (2003) The effect of queen pheromones on worker honey bee ovary development. Naturwissenschaften, 90, 477-480.

Hoover SER, Higo HA, Winston ML (2006) Worker honey bee ovary development: seasonal variation and the influence of larval and adult nutrition. Journal of Comparative Physiology B-Biochemical Systemic and Environmental Physiology, 176, 5563.

Hummon AB, Richmond TA, Verleyen P et al. (2006) From the genome to the proteome: uncovering peptides in the Apis brain. Science, 314, 647-649.

Hunt GJ, Amdam GV, Schlipalius D et al. (2007) Behavioral genomics of honeybee foraging and nest defense. Naturwissenschaften, 94, 247-267.

Kocher SD, Richard FJ, Tarpy DR et al. (2008) Genomic analysis of post-mating changes in the honey bee queen (Apis mellifera). BMC Genomics, 9, 232.

Kocher SD, Ayroles JF, Stone EA et al. (2010) Individual variation in pheromone response correlates with reproductive traits and brain gene expression in worker honey bees. PLOS ONE, 5, e9116.

Kubo T, Sasaki M, Nakamura J et al. (1996) Change in the expression of hypopharyngeal-gland proteins of the worker honeybees (Apis mellifera L) with age and/or role. Journal of Biochemistry, 119, 291-295.

Kucharski R, Maleszka J, Foret S et al. (2008) Nutritional control of reproductive status in honeybees via DNA methylation. Science, 319, 1827-1830.

Lindemans M, Liu F, Janssen T et al. (2009) Adipokinetic hormone signaling through the gonadotropin-releasing hormone receptor modulates egg-laying in Caenorhabditis elegans. Proceedings of the National Academy of Sciences of the United States of America, 106, 1642-1647.

Linksvayer TA, Rueppell O, Siegel A et al. (2009) The genetic basis of transgressive ovary size in honeybee workers. Genetics, 183, 693-707.

Maisonnasse A, Lenoir JC, Beslay D et al. (2010) E-betaocimene, a volatile brood pheromone involved in social regulation in the honey bee colony (Apis mellifera). PLoS ONE, 5, e13531.

Martin SJ, Beekman M, Wossler TC et al. (2002) Parasitic Cape honeybee workers, Apis mellifera capensis, evade policing. Nature, 415, 163-165.

Miller DG, Ratnieks FLW (2001) The timing of worker reproduction and breakdown of policing behaviour in queenless honey bee (Apis mellifera L.) societies. Insectes Sociaux, 48, 178-184.

Mohammedi A, Paris A, Crauser D et al. (1998) Effect of aliphatic esters on ovary development of queenless bees (Apis mellifera L.). Naturwissenschaften, 85, 455-458.

Oldroyd BP, Beekman M (2008) Effects of selection for honey bee worker reproduction on foraging traits. PLoS Biology, 6, e56.

Oxley PR, Thompson GJ, Oldroyd BP (2008) Four quantitative trait loci that influence worker sterility in the honeybee (Apis mellifera). Genetics, 179, 1337-1343.
Palmer KA, Oldroyd BP (2000) Evolution of multiple mating in the genus Apis. Apidologie, 31, 235-248.

Park JM, Kunieda T, Kubo T (2003) The activity of Mblk-1, a mushroom body-selective transcription factor from the honeybee, is modulated by the Ras/MAPK pathway. Journal of Biological Chemistry, 278, 18689-18694.

Patel A, Fondrk MK, Kaftanoglu O et al. (2007) The making of a queen: TOR pathway is a key player in diphenic caste development. PLoS ONE, 2, e509.

Queller DC (2003) Theory of genomic imprinting conflict in social insects. BMC Evolutionary Biology, 3, 15.

Rachinsky A, Hartfelder K (1990) Corpora allata activity, a prime regulating element for caste-specific juvenile-hormone titer in honey-bee larvae (Apis-mellifera-carnica). Journal of Insect Physiology, 36, 189-194.

Rachinsky A, Strambi C, Strambi A et al. (1990) Caste and metamorphosis - hemolymph titers of juvenile-hormone and ecdysteroids in last instar honeybee larvae. General and Comparative Endocrinology, 79, 31-38.

Ratnieks FLW (1988) Reproductive harmony via mutual policing by workers in eusocial hymenoptera. American Naturalist, 132, 217-236.

Ratnieks FLW (1993) Egg-laying, egg-removal, and ovary development by workers in queenright honey-bee colonies. Behavioral Ecology and Sociobiology, 32, 191-198.

Ratnieks FLW, Visscher PK (1989) Worker policing in the honeybee. Nature, 342, 796-797.

Ratnieks FL, Wenseleers T (2008) Altruism in insect societies and beyond: voluntary or enforced? Trends in Ecology $\mathcal{E}$ Evolution, 23, 45-52.

Ratnieks FLW, Foster KR, Wenseleers T (2011) Darwin's special difficulty: the evolution of "neuter insects" and current theory. Behavioral Ecology and Sociobiology, 65, 481492.

Rembold H (1987) Caste specific modulation of juvenilehormone titers in Apis-mellifera. Insect Biochemistry, 17, 10031006.

Robinson GE, Huang ZY (1998) Colony integration in honey bees: genetic, endocrine and social control of division of labor. Apidologie, 29, 159-170.

Robinson GE, Vargo EL (1997) Juvenile hormone in adult eusocial hymenoptera: gonadotropin and behavioral pacemaker. Archives of Insect Biochemistry and Physiology, 35, 559-583.

Robinson GE, Strambi C, Strambi A et al. (1991) Comparison of juvenile-hormone and ecdysteroid hemolymph titers in adult worker and queen honey-bees (Apis-mellifera). Journal of Insect Physiology, 37, 929-935.

Robinson GE, Strambi C, Strambi A et al. (1992) reproduction in worker honey-bees is associated with low juvenilehormone titers and rates of biosynthesis. General and Comparative Endocrinology, 87, 471-480.

Sakagami SF, Akahira Y (1958) Comparison of ovarian size and number of ovarioles between the workers of Japanese and European honeybees. Kontyu, 26, 103-109.

Santos KS, dos Santos LD, Mendes MA et al. (2005) Profiling the proteome complement of the secretion from hypopharyngeal gland of Africanized nurse-honeybees (Apis mellifera L.). Insect Biochemistry and Molecular Biology, 35, 8591. 
Schafer MO, Dietemann V, Pirk CWW et al. (2006) Individual versus social pathway to honeybee worker reproduction (Apis mellifera): pollen or jelly as protein source for oogenesis? Journal of Comparative Physiology A-Neuroethology Sensory Neural and Behavioral Physiology, 192, 761-768.

Slessor KN, Winston ML, Le Conte Y (2005) Pheromone communication in the honeybee (Apis mellifera L.). Journal of Chemical Ecology, 31, 2731-2745.

Smyth G (2005) Limma: linear models for microarray data. Bioinformatics and computational biology solutions using $\mathrm{R}$ and Bioconductor. Springer, New York, pp. 397-420.

Snodgrass RE (1984) Anatomy of the honey bee. 1-334.

The Honeybee Genome Sequencing Consortium (2006) Insights into social insects from the genome of the honeybee Apis mellifera. Nature, 443, 931-949.

Thompson GJ, Kucharski R, Maleszka R et al. (2006) Towards a molecular definition of worker sterility: differential gene expression and reproductive plasticity in honey bees. Insect Molecular Biology, 15, 637-644.

Thompson GJ, Yockey H, Lim J et al. (2007) Experimental manipulation of ovary activation and gene expression in honey bee (Apis mellifera) queens and workers: testing hypotheses of reproductive regulation. Journal of Experimental Zoology Part A-Ecological Genetics and Physiology, 307, 600610.

Thompson GJ, Kucharski R, Maleszka R et al. (2008) Genomewide analysis of genes related to ovary activation in worker honey bees. Insect Molecular Biology, 17, 657-665.

Toth AL, Varala K, Henshaw MT et al. (2010) Brain transcriptomic analysis in paper wasps identifies genes associated with behaviour across social insect lineages. Proceedings of the Royal Society B-Biological Sciences, 277, 21392148.

Wanner KW, Nichols AS, Walden KKO et al. (2007) A honey bee odorant receptor for the queen substance 9-oxo-2decenoic acid. Proceedings of the National Academy of Sciences, USA, 104, 14383-14388

Weaver RJ, Audsley N (2009) Neuropeptide regulators of juvenile hormone synthesis. Annals of the New York Academy of Sciences, 1163, 316-329.

Wenseleers T, Ratnieks FL (2006) Enforced altruism in insect societies. Nature, 444, 50.

Wheeler DE, Buck N, Evans JD (2006) Expression of insulin pathway genes during the period of caste determination in the honey bee, Apis mellifera. Insect Molecular Biology, 15, 597602.

Whitfield CW, Cziko AM, Robinson GE (2003) Gene expression profiles in the brain predict behavior in individual honey bees. Science, 302, 296-299.

Whitfield CW, Ben-Shahar Y, Brillet C et al. (2006) Genomic dissection of behavioral maturation in the honey bee. Proceedings of the National Academy of Sciences, USA, 103, 16068-16075.

Winston ML (1987) The biology of the honey bee, Harvard University, Cambridge, Massachusetts.

Wolschin F, Amdam GV (2007) Comparative proteomics reveal characteristics of life-history transitions in a social insect. Proteome Science, 5, 10.

Yamanaka N, Yamamoto S, Zitnan D et al. (2008) Neuropeptide receptor transcriptome reveals unidentified neuroendocrine pathways. PLoS ONE, 3, e3048.
D.C. specializes on the physiological background of worker reproduction. T.W.'s research focuses on social evolution and the evolution of conflict and cooperation in insect societies. U.E. is interested in social insects and the interplay between physiology and ecology. E.L.D. is working on the effects of venom from the ectoparasitic wasp Nasonia vitripennis on the immune system of its host. D.dG. is a Senior Lecturer in the Department of Physiology at the Ghent University, Belgium. His research involves proteomics of Hymenopteran venoms and different aspects of the pathology and immunology of honey bees and bumble bees. L.S.'s professional interests are neuronal circuits, physiology and behaviour in invertebrates. P.V. is specialized in peptidomics and proteomics with an emphasis on the developmental, immunological and/or reproductive physiology of different invertebrate models.

\section{Data accessibility}

All microarray data are available at http://www.ebi.ac.uk/arrayexpress, access nr. E-TABM-1003.

\section{Supporting information}

Additional supporting information may be found in the online version of this article.

Tables S1 List of genes which were differentially expressed between reproductive and nonreproductive workers, together with functional annotation information

Tables S2 Association tests between our differentially expressed gene sets and various other candidate gene sets, calculated using exact hypergeometric one-way Fisher exact tests or one-way Spearman rank correlation tests

Tables S3 Biological processes gene ontology (GO) terms overrepresented among the sets of genes that were upregulated in reproductive and nonreproductive workers, calculated using TopGO

Tables S4 Results of technical (same samples of the microarray analysis) and biological (different samples) validation experiment by means of quantitative Real time Polymerase Chain Reaction (qRT-PCR), using protocols described in Data S1

Tables S5 Primers for the validation experiments using qRTPCR, specific for the candidate reference genes and the target genes

Data S1 Methods.

Data S2 Results.

Data S3 References.

Please note: Wiley-Blackwell are not responsible for the content or functionality of any supporting information supplied by the authors. Any queries (other than missing material) should be directed to the corresponding author for the article. 